\title{
Variation in the CACNB2 gene is associated with functional connectivity of the Hippocampus in bipolar disorder
}

Fang Liu ${ }^{1,2+}$, Xiaohong Gong ${ }^{3 \dagger}$, Xudong Yao ${ }^{1,2}$, Lingling Cui ${ }^{4}$, Zhiyang Yin ${ }^{1}$, Chao Li ${ }^{4}$, Yanqing Tang ${ }^{1,5^{*}}$ and Fei Wang ${ }^{1,4,6^{*}}$

\begin{abstract}
Background: Calcium voltage-gated channel auxiliary subunit $\beta 2$ is a protein that, in humans, is encoded by the CACNB2 gene. The $\beta 2$ subunit is an auxiliary protein of voltage-gated calcium channels, which is predominantly expressed in hippocampal pyramidal neurons. A single-nucleotide polymorphism at the CACNB2 gene (rs11013860) has been reported in genome-wide association studies to be associated with bipolar disorder (BD). However, the neural effects of rs 11013860 expression are unknown. Thus, the current study investigated the mechanisms of how the CACNB2 gene influences hippocampal-cortical limbic circuits in patients with bipolar disorder (BD).

Methods: A total of 202 subjects were studied [69 BD patients and 133 healthy controls (HC)]. Participants agreed to undergo resting-state functional magnetic resonance imaging (rs-fMRI) and have blood drawn for genetic testing. Participants were found to belong to either a CC group homozygous for the C-allele (17 BD, $41 \mathrm{HC})$, or an A-carrier group carrying the high risk A-allele (AA/CA genotypes; 52 BD, $92 \mathrm{HC}$ ). Brain activity was assessed using resting-state functional connectivity (rs-FC) analyses.
\end{abstract}

Results: A main effect of genotype showed that the rs-FC of the AA/CA group was elevated more than that of the CC-group between the hippocampus and the regions of right-inferior temporal, fusiform, and left-inferior occipital gyri. Additionally, a significant diagnosis $\times$ genotype interaction was noted between the hippocampus and right pars triangularis. Furthermore, in BD patients, the AA/CA group showed lower rs- $F C$ when compared to that of the CC group. Additionally, individuals from HC within the AA/CA group showed higher rs-FC than that of the CC group. Finally, within C-allele-carrying groups, individuals with BD showed significantly increased rs-FC compared to that of $\mathrm{HC}$.

Conclusions: Our study demonstrates that BD patients with the CACNB2 rs11013860 AA/CA genotype may exhibit altered hippocampal-cortical connectivity.

Keywords: CACNB2, 11,013,860, Bipolar disorder, Resting-state functional connectivity (rs-FC)

\section{Background}

Mental illnesses are complex conditions that affect a substantial portion of the population. Primary symptoms include abnormalities in perception and cognition that result in behavioral and volitional impairments [1]. Bipolar disorder $(\mathrm{BD})$ is a relatively common mental illness

\footnotetext{
* Correspondence: yanqingtang@163.com; fei.wang@cmu.edu.cn ${ }^{\dagger}$ Fang Liu and Xiaohong Gong contributed equally to this work. ${ }^{1}$ Department of Psychiatry, First Affiliated Hospital, China Medical University, 155 Nanjing North Street, Shenyang 110001, Liaoning, China Full list of author information is available at the end of the article
}

that is highly heritable, leading to the general belief that genes are an important risk factor [2]. The biomarker rs11013860 has been reported to be associated with BD. This biomarker is located in the CACNB2 gene, which encodes for the $\beta$ subunit of voltage-gated calcium channels $\left(\mathrm{Ca}_{\mathrm{v}}\right)$ and has been shown to be expressed in hippocampal pyramidal neurons in Han Chinese individuals [3]. The CACNB2 gene, which is located at $10 \mathrm{p} 12$, spanning an approximately $398.5 \mathrm{~kb}$ genomic region, consists of 14 exons. CACNB2 encodes an auxiliary $\mathrm{Ca}_{\mathrm{v}}$ subunit which interacts with L-type calcium-channel subunits to

(c) The Author(s). 2019 Open Access This article is distributed under the terms of the Creative Commons Attribution 4.0 International License (http://creativecommons.org/licenses/by/4.0/), which permits unrestricted use, distribution, and 
promote their trafficking to the plasma membrane, increase their function, and regulate their modulation by other signaling proteins and molecules [4, 5]. CACNB2 variation provides a promising link for investigating the potential underlying molecular mechanisms of $\mathrm{BD}$. One genome-wide association (GWAS) study of BD in the Han Chinese population found that rs11013860 in the CACNB2 gene is associated with BD-I $\left(p=5.15^{*} 10^{-5}\right)$ [6]. A separate study conducted joint analyses of four markers (CACNA1C rs10848635, CACNA1E rs10848635, $C A C N B 2$ rs11013860, and $C A C N G 2$ rs $2,284,018)$ and found higher accumulative risk in individuals diagnosed with BD-I $\left(p_{\text {trend }}=0.006\right)$ and BD-II $\left(p_{\text {trend }}=0.017\right)$. Combined analysis with independent-replication samples further supported the association of rs11013860 with BP-I $(p<0.001)$ [7]. Accumulating evidence suggests that gene alterations of $C A C N B 2$ in the hippocampus may cause changes to hippocampal circuitry, resulting in dysfunction of hippocampal neuroconnectivity similar to what is observed in BD. However, how rs11013860 may mediate this association is unknown.

Resting-state functional magnetic resonance imaging (rs-fMRI) is a promising tool for investigating the intrinsic functional connections among anatomically distinct brain regions within specific neural networks [8]. The intrinsic functional connectivity (FC) of hippocampal networks has been identified using rs-fMRI under both healthy and pathological conditions [9]. Further, genetic imaging technology has been utilized to explore the relationship between $C A C N B 2$ gene polymorphisms and brain activity $[10,11]$, and to identify neural circuits linked to the genetic risk for heritable neuropsychiatric disorders [12]. As previous studies have confirmed that both the $C A C N B 2$ gene is associated with $\mathrm{BD}$, and that the $C A C N B 2$ gene is distributed in hippocampal pyramidal neurons [3], the hippocampus was chosen as the region of interest (ROI) in the current study. We examined the hippocampus to identify any mediating effects of CACNB2 rs11013860 on hippocampal-cortical connectivity in $\mathrm{BD}$.

\section{Materials and methods \\ Subjects}

The current study was approved by the Ethics Committee of First Affiliated Hospital of China Medical University (Shenyang China). Each participant provided written informed consent prior to commencement of the study. If their age was less than 18-years-old, they and their parental/legal guardian also provided written informed consent. Sixty-nine BD patients (mean age $=27.19 \pm 9.46$ years, $68.12 \%$ female) and 133 healthy controls (mean age = $28.52 \pm 8.07$ years, $60.15 \%$ female) were recruited to undergo rs-fMRI and genetic testing. The $\mathrm{BD}$ patients were comprised of $31 \mathrm{BD}-\mathrm{I}$ (mean age $=29.58 \pm 9.05$ years,
$64.52 \%$ female) and 38 BD-II (mean age $=25.66 \pm 9.75$ years, $71.05 \%$ female), which were recruited from the outpatient clinics of the Department of Psychiatry at First Affiliated Hospital of China Medical University (Shenyang China). Healthy control (HC) participants were recruited from Shenyang (China) using a community advertisement. All HC met the following criteria: (1) age between 13 and 59 years; (2) no history of neuropsychiatric or other severe diseases; (3) no history of head injury; (4) no MRI-scan limitations. All BD patients met criteria for BD diagnosis delineated in the Diagnostic and Statistical Manual of Mental Disorders, Fourth Edition (known as the DSM-IV) according to a diagnostic assessment which fulfilled guidelines in the Structured Clinical Interview for DSM-IV, Patient Edition. Diagnosis was determined by two experienced clinical psychiatrists. Exclusion criteria included the presence of the following: (1) any history of major bodily disease; (2) any history of moderate or severe head injury, head trauma, neurologic disorder, or mental retardation; (3) alcohol or substance abuse or dependence; and/or (4) the presence of a concurrent and major physical illness that could lead to mood disorder symptoms. The control subjects were interviewed using the Structured Clinical Interview for the DSM-IV, Non-patient edition (SCID-I/ $\mathrm{NP})$ to ensure no presence of $\mathrm{BD}$ or other psychiatric disorders.

\section{Extraction and genotyping}

Ten-milliliter blood samples were collected from participants for DNA extraction. Genotypes of single nucleotide polymorphisms (SNPs) at rs11013860 were determined using the Sanger sequencing method. Subjects were further divided into two groups: a CC-allele group (CC genotypes; $17 \mathrm{BD}, 41 \mathrm{HC}$; mean age $=29.14 \pm 8.35$ years, $67.24 \%$ female) and risk A-carrier group (AA/CA genotypes; 52 $\mathrm{BD}, 92 \mathrm{HC}$; mean age $=27.88 \pm 8.68$ years, $61.97 \%$ female) . Minor allele frequencies were $0.45 \%$. Genotype frequencies were consistent with Hardy-Weinberg equilibrium (HWE) expectations (BD: $\chi^{2}=1.24, p=0.26$; HC: $\left.\chi^{2}=0.21, p=0.65\right)$.

\section{fMRI data acquisition}

A GE Signa HDX (U.S.A.) 3.0 T MRI scanner at the First Affiliated Hospital of China Medical University (Shenyang, China) was used to acquire rs-fMRI data. Head motion was minimized with restraining foam pads. Soft pads and earplugs were used during scanning to restrict head motion and reduce scanner noise. Participants were asked to keep their eyes closed, but remain awake during the scan. A gradient-echo planar imaging (EPI) sequence parallel to the AC-PC plane was used to obtain rs-fMRI images, with the following scan parameters: repetition time $(\mathrm{TR})=2000 \mathrm{~ms}$; echo time $(\mathrm{TE})=40 \mathrm{~ms}$; image matrix $=64 \times 64$; field of view $(\mathrm{FOV})=24 \times 24 \mathrm{~cm}^{2} ; 35$ 
contiguous slices of $3 \mathrm{~mm}$ without gap; scan time $=6$ $\min 40 \mathrm{~s}$.

\section{Image analysis and processing}

Preprocessing of rs-fMRI data was conducted using SPM12 (www.fil.ion.ucl.ac.uk/spm/software/spm12) and the rs-fMRI processing and analysis toolbox (DPABI; http://rfmri.org/dpabi). The first 10 images were deleted due to magnetic saturation effects. The remaining data were then further preprocessed, which included slice-timing correction, head-motion correction, spatial normalization, and smoothing. Head motion parameters were computed by estimating translation in each direction and angular rotation about each axis for each volume. According to the record of head motion within each rs-fMRI run, participants were excluded if their head motion was $>2.5 \mathrm{~mm}$ maximal displacement in any of the $\mathrm{x}, \mathrm{y}$, or $\mathrm{z}$ directions, or $2.5^{\circ}$ of any angular motion throughout the course of the scan [13]. Subsequent data preprocessing included removal of linear trends and temporal filtering (band pass, $0.01-0.08 \mathrm{~Hz}$ ) to reduce the effects of low-frequency drift and high-frequency noise. Linear regression of head motion parameters, global mean signal, white matter signal, and cerebrospinal fluid signal were performed to remove effects of these covariates.

\section{ROI-based functional connectivity analysis}

The bilateral hippocampus ROI was defined according to the automated anatomical labeling (AAL) template [14]. For each subject, the ROI time series was extracted as the mean time series across all voxels within that region [15]. The time series of each ROI was correlated with those of the whole brain. The Pearson correlational coefficient $(r)$ was obtained by the voxel-voxel method. Finally, normality of the data was improved by converting $r$ values to $z$ values through Fisher's $r$-to- $z$ transformation.

\section{Statistical analysis}

Demographic data (sex, age, education) were analyzed using $t$-tests with diagnostic groups $(\mathrm{BD}, \mathrm{HC})$ and genotype groups (CC, AA/CA) as between-subject factors. An analysis of variance (ANOVA) was used to compare different genotypes between the BD and HC groups. All statistical analyses were performed using SPSS 22.0 software.

A voxel wise ANOVA $(2 \times 2$ ANOVA: diagnosis $\times$ genotypes) was used to determine the effects of diagnosis and genotype on FC, and age and sex were considered covariates. A post hoc $t$-test was used to explore main effects and interactions. The contrast map threshold was set at $p<0.01$ for each voxel, with a cluster size of at least 49 voxels $\left(1323 \mathrm{~mm}^{3}\right)$, which was equal to the corrected threshold of $p<0.05$, as determined by Gaussian random field (GRF).

\section{Results \\ Participant characteristics}

There were no significant effects for age or sex among $\mathrm{BD}$ and $\mathrm{HC}$ participants (Table 1).

\section{Resting-state functional connectivity (rs-FC)}

Influence of diagnosis and genotype on rs-FC between $\mathrm{CC}$ and $\mathrm{AA} / \mathrm{CA}$ genetic subgroups in $\mathrm{BD}$ and $\mathrm{HC}$ are listed in Table 2.

After performing a one-way ANOVA on the FC maps, the main effect of diagnosis was not statistically significant. However, there was a significant main effect of genotype between the hippocampus and the regions of the right-inferior temporal and right fusiform gyri $(t=3.91$ $p<0.001$, corrected) and left fusiform/left inferior occipital gyri $(t=4.11 p<0.001$, corrected; Fig. 1$)$. Individuals carrying high-risk A-allele exhibited higher rs-FC than individuals carrying the C-allele (Fig. 3a). Additionally, there was a significant interaction of genotype-by-diagnosis between the hippocampus and right pars triangularis $(\mathrm{F}=7.08, p<0.001$, corrected; Fig. 2). Further, in $\mathrm{BD}$ patients, the AA/CA group showed lower rs-FC than that of the CC group. Additionally, in individuals with $\mathrm{HC}$, the $\mathrm{AA} / \mathrm{CA}$ group showed higher rs-FC than that of the CC group. Finally, in $\mathrm{C}$-allele-carrying groups, the patients with $\mathrm{BD}$ had significantly increased rs-FC compared to that of the CC group (Fig. 3b).

\section{Discussion}

L-type calcium channels (LTCCs) are widely expressed in the central nervous system, and have been shown to influence neurotransmitter release and neuronal excitability [16]. Studies have shown that altered calcium levels in cells might affect vulnerability (i.e. impaired resilience) observed in neurons of patients with $\mathrm{BD}[6,17]$. LTCCs are formed by the principal $\chi^{1}$ subunits with auxiliary $\chi^{2} \delta$ and cytosolic $\beta$, $\gamma$ subunits [3]. The $\beta$ subunit is coded by $C A C N B 2$ genes, which are distributed only in hippocampal pyramidal, thalamic, and cerebellar Purkinje cells in the brain $[3,18,19]$.

In the last few years, both GWAS and Integrated Pathway-Based Studies have identified associations between SNPs in CACNB2 and serious mental disorders, including $B D[6,7,20]$. A study by Soldatov found that CACNB2 modulated Cav1.2 channels and showed decreased and incomplete inactivation of calcium currents, possibly causing neuronal dysregulation related to the parthenogenesis of BD [21]. More recent evidence suggests that the alteration of $C A C N B 2$ rs11013860 may be a molecular mechanism of genetic risk in BD [6]. 
Table 1 Demographic and clinical data of participants

\begin{tabular}{|c|c|c|c|c|c|}
\hline Characteristics & Genotype & $\mathrm{HC}(n=133)$ & $\mathrm{BD}(n=69)$ & $t / x^{2}$ & $p$ value \\
\hline \multirow[t]{3}{*}{ Age (years) } & AA & $29.79 \pm 9.16$ & $28.23 \pm 7.68$ & 1.04 & 0.30 \\
\hline & CA & $28.14 \pm 8.21$ & $25.62 \pm 9.44$ & & \\
\hline & CC & $28.39 \pm 7.25$ & $30.94 \pm 10.60$ & & \\
\hline \multirow[t]{3}{*}{ Sex (M:F) } & AA & $11: 13$ & $4: 9$ & 1.29 & 0.26 \\
\hline & CA & $28: 40$ & 13:26 & & \\
\hline & CC & $14: 27$ & $5: 12$ & & \\
\hline Education level (years) & & $14.92 \pm 3.40$ & $13.03 \pm 3.11$ & - & - \\
\hline Handedness (Right/Left/Both) & & $127 / 5 / 1$ & $66 / 2 / 1$ & - & - \\
\hline Medication, yes & & - & $52(75.36 \%)$ & & \\
\hline Anti-depressants & & - & $25(36.23 \%)$ & & \\
\hline Antipsychotics & & - & $30(43.48 \%)$ & & \\
\hline Mood stabilizer & & - & $48(57.97 \%)$ & & \\
\hline \multirow[t]{2}{*}{ HWE } & $x^{2}$ & 0.21 & 1.24 & - & - \\
\hline & $p$ value & 0.65 & 0.26 & - & - \\
\hline \multirow[t]{2}{*}{ Allele } & A-allele & $116(0.44)$ & $65(0.47)$ & - & - \\
\hline & C-allele & $150(0.56)$ & $73(0.53)$ & - & - \\
\hline
\end{tabular}

Data are presented as mean \pm SD (Standard deviation)

In our study, we did not observe abnormal neural circuits between $\mathrm{BD}$ and $\mathrm{HC}$. This may be related to sample size, medication, and/or disease status. However, genotype was found to be associated with neural connectivity between the hippocampus and the regions of right inferior temporal, fusiform, and left inferior occipital gyri. Individuals carrying the high-risk A-allele exhibited higher rs-FC than individuals carrying the $\mathrm{C}$-allele. Early research has confirmed that there are cellular connections from the temporal gyrus to the hippocampal area [22], and that this region is associated with processing memory, as well as visual and linguistic information. It is possible that carrying this risk gene may result in impairment of these functions. The fusiform gyrus is related to positive task activation in cognitive behaviors, such as object, face, body, and character recognition [23-25]. Additionally, the inferior occipital gyrus has been shown to be related to association and recognition memory [26, 27]. The increased excitability of the A-allele risk gene in the neural circuitry between these brain regions and the hippocampus suggests that carrying the risk gene could lead to dysfunction, possibly impairing social function and memory.

Additionally, the current study observed significant interactions between rs11013860 genotypes and diagnoses between $\mathrm{BD}$ and $\mathrm{HC}$ groups within the neural circuits of the hippocampus and right pars triangularis. In $\mathrm{BD}$ patients carrying the A- risk gene, rs-FC was decreased when compared to that of patients carrying the $\mathrm{C}$-allele. In $\mathrm{C}$-allele-carrying groups, patients with BD had significantly increased rs-FC compared to that of HC. Our findings suggest that the excitability of the neural circuitry underlying the condition of gene-disease interactions may have different results. And the potential abnormalities of the neural circuits between the hippocampus and right pars triangularis in BD patients with the A- risk group suggest that the risk A allele is

Table 2 Clusters exhibiting the influence of group and genotype on the values of FC between CC and CA/AA genetic subgroups in $\mathrm{BD}$ and $\mathrm{HC}$

\begin{tabular}{|c|c|c|c|c|c|}
\hline \multirow[t]{2}{*}{ Brain area } & \multirow{2}{*}{$\begin{array}{l}\text { Cluster } \\
\text { size }\end{array}$} & \multicolumn{3}{|c|}{ Peak MNI coordinates } & \multirow[t]{2}{*}{ Peak F value } \\
\hline & & $\bar{x}$ & $Y$ & Z & \\
\hline \multicolumn{6}{|l|}{ Main effect of genotypes } \\
\hline right inferior temporal/right fusiform gyri & 80 & 48 & -57 & -18 & 12.07 \\
\hline left fusiform/left inferior occipital gyri & 50 & -39 & -72 & -15 & 23.25 \\
\hline \multicolumn{6}{|l|}{ Diagnostic groups $\times$ genotype interaction } \\
\hline right pars triangularis & 128 & 54 & 33 & 9 & 19.31 \\
\hline
\end{tabular}

These findings correspond to a corrected $p<0.01$ by GRF correction. Cluster size is in $\mathrm{mm}^{3}$ 


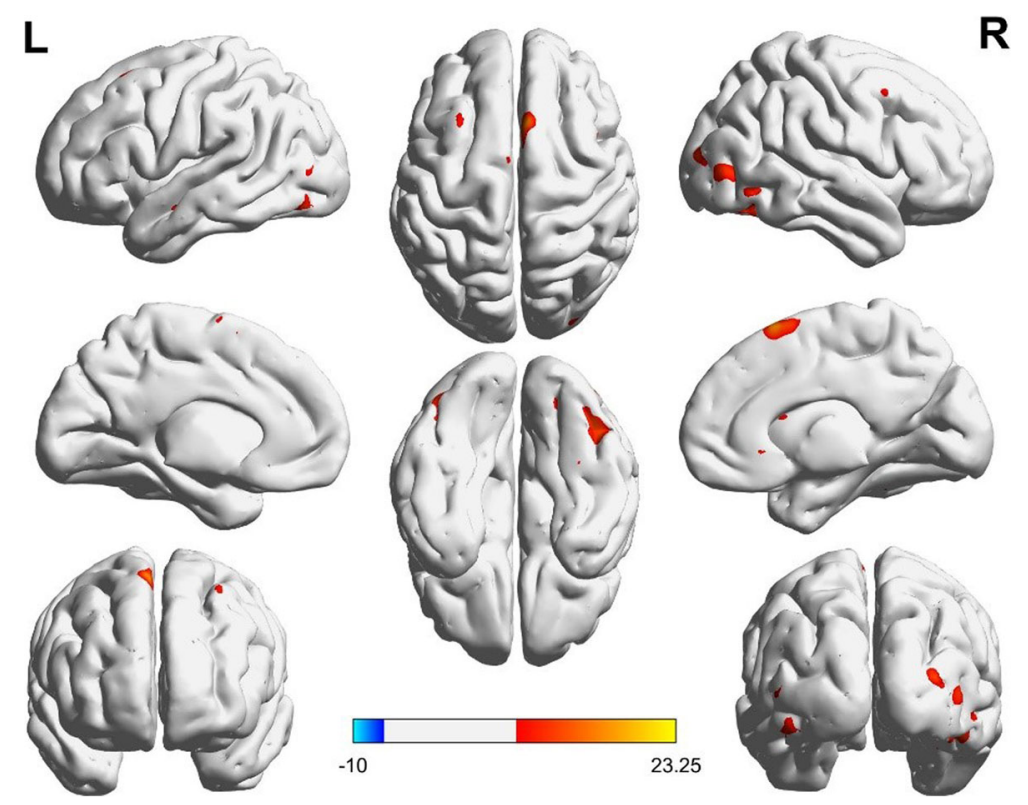

Fig. 1 Main effect of genotype on the rs-FC between AA/CA group and CC group. Clusters presenting lower (blue) or higher (red) rs-FC, $p<0.01$ GRF-corrected

associated with frontal-hippocampal cortical dysfunction activity in BD.

The pars triangularis is involved in a specific type of language processing and plays a role in the cognitive control of memory [28-30], and is a part of the prefrontal cortex. Anatomical studies have shown that there are complex neural projections between the hippocampus and the prefrontal cortex [31, 32], which participate in a variety of cognitive functions and are associated with the occurrence of a variety of mental disorders [22, 23, 33]. Our study showed impaired prefrontal-hippocampal cortical neuroconnectivity in patients with $\mathrm{BD}$ that also carried the A allele. Previous studies have found that dysregulation of $\mathrm{Ca}^{2+}$ signaling pathways has been implicated in the development of $\mathrm{BD}$ [24]. In patients with $\mathrm{BD}$, voltage-gated $\mathrm{Ca}^{2+}$ channels

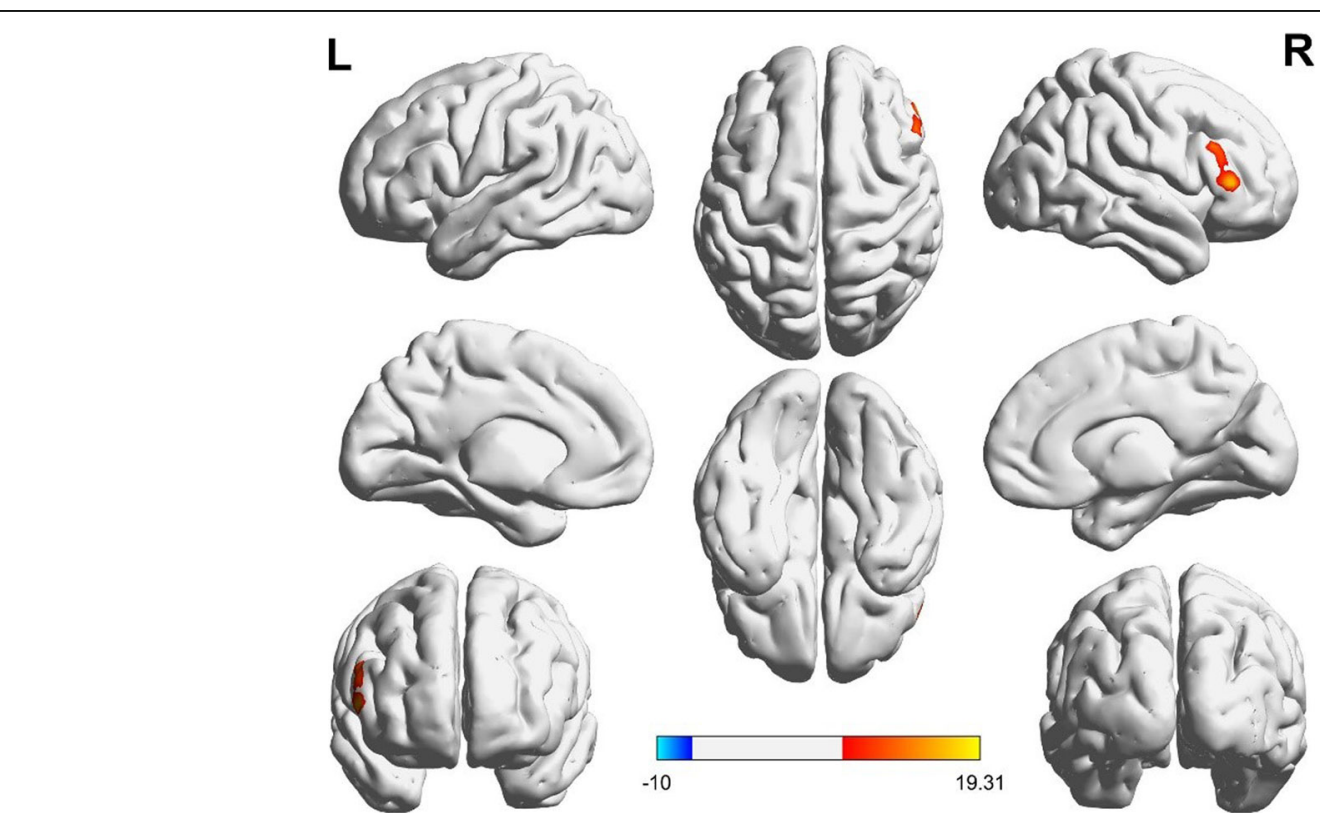

Fig. 2 Interaction between rs11013860 genotype and diagnosis in BD and HC. Clusters presenting lower (blue) or higher (red) rs-FC, $p<0.01$ GRF-corrected 


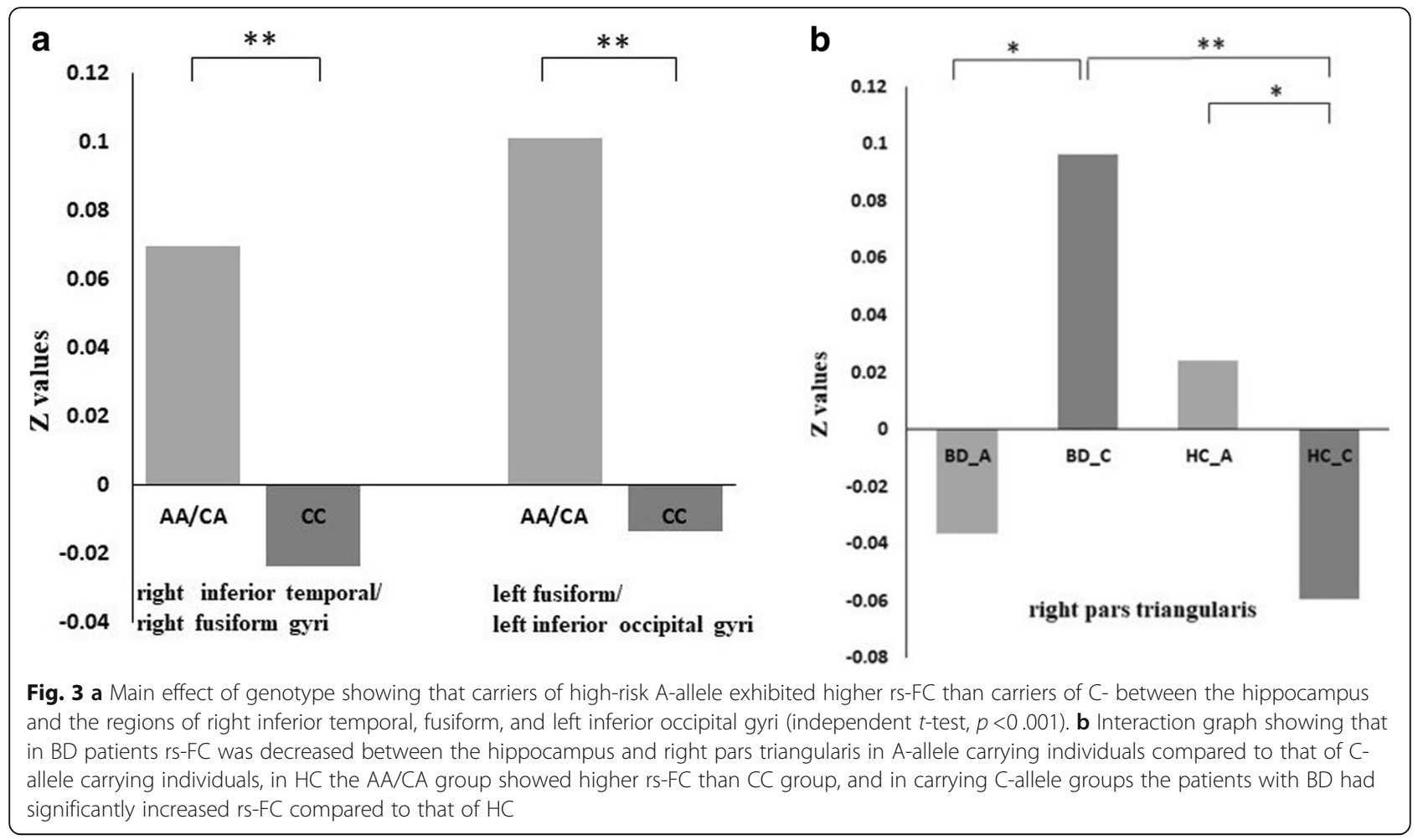

can be activated by membrane depolarization, resulting in increased neuronal excitability [25]. The CACNB2 results in the changing of channel activity by encoding the $\mathrm{Ca}^{2+}$ channel $\beta$-subunit, regulating the intensity of current of the $\mathrm{Ca}^{2+}$ channel, and controlling the membrane characterization of the $x 1$ subunit $[3,21]$. Therefore, it is possible that the interaction between gene and disease brings the neural circuitry between hippocampus and right pars triangularis back to normal.

However, it remains unknown when and how this interaction could change the neural circuitry in the brain. Many factors could influence the occurrence and development of $\mathrm{BD}$, which have been well established as risk factors for the occurrence of disease [26, 27].

\section{Conclusion}

In summary, the present study demonstrated, for the first time, that CACNB2 rs11013860 AA/CA genotype may affect regional brain activity in $\mathrm{BD}$ patients. This suggests that the influence of $C A C N B 2$ variation may be one mechanism that contributes to the neural circuitry of BD.

\section{Abbreviations}

AA/CA: high-risk genetic subgroup; AAL: automated anatomical labeling; BD: Bipolar disorder; Cav: voltage-gated calcium channels; CC: allele genetic subgroup; FC: functional connectivity; GWA: genome-wide association; HC: Healthy controls; HWE: Hardy-Weinberg equilibrium; LTCC: L-type calcium channels; ROI: region of interest; rs-FC: resting-state functional connectivity; rs-fMRI: resting-state functional magnetic resonance imaging
Acknowledgments

We thank the participants for their help with the study.

Funding

National Natural Science Foundation of China (81571311, 81071099 and 81271499 to Y.T., 81571331 to F.W.), Liaoning Pandeng Scholar (to F.W.), the National Institution of Health (K01MH086621 to F.W.). The funding body did not participate in design, conduct, or writing of the study.

Availability of data and materials

The datasets we applied are available from the corresponding author, provided reasonable requests.

\section{Authors' contributions}

$F W, Y T$ and $F L$ designed the experiment. $X G, X Y, L C$ and $Z Y$ acquired the data. $F L, X G, C L$ and $L C$ analyzed the data. FW, $Y T, X G$ and $F L$ wrote the manuscript. All the authors discussed the results and reviewed the manuscript. All authors read and approved the final manuscript.

Ethics approval and consent to participate

The study was conducted in accordance with the latest version of the Declaration of Helsinki and approved by the Institutional Review Board of the China Medical University. Each participant provided written informed consent prior to commencement of the study.

Consent for publication

Not applicable.

Competing interests

The authors declare that they have no competing interest.

\section{Publisher's Note}

Springer Nature remains neutral with regard to jurisdictional claims in published maps and institutional affiliations. 


\section{Author details}

'Department of Psychiatry, First Affiliated Hospital, China Medical University, 155 Nanjing North Street, Shenyang 110001, Liaoning, China. ${ }^{2}$ The Clinical Hospital of Chengdu Brain Science Institute, MOE Key Lab for Neuroinformation, University of Electronic Science and Technology of China, Chengdu, China. ${ }^{3}$ A605, Building School of Life SCiences, Songhu Road 2005, Dinstric Yangpu, Shanghai, China. ${ }^{4}$ Department of Radiology, First Affiliated Hospital, China Medical University, Shenyang, Liaoning, People's Republic of China. ${ }^{5}$ Department of Geriatric Medicine, First Affiliated Hospital, China Medical University, Shenyang, Liaoning, People's Republic of China. ${ }^{6}$ Brain Function Research Section, First Affiliated Hospital, China Medical University, Shenyang, Liaoning, People's Republic of China.

Received: 21 October 2018 Accepted: 28 January 2019

Published online: 11 February 2019

\section{References}

1. Jeste DV, Palmer BW, Rettew DC, Boardman S. Positive psychiatry: its time has come. J Clin Psychiatry. 2015;76(6):675-83.

2. Lotan A, Fenckova M, Bralten J, Alttoa A, Dixson L, Williams RW, van der Voet M. Neuroinformatic analyses of common and distinct genetic components associated with major neuropsychiatric disorders. Front Neurosci. 2014;8:331.

3. Vacher H, Mohapatra DP, Trimmer JS. Localization and targeting of voltagedependent ion channels in mammalian central neurons. Physiol Rev. 2008; 88(4):1407-47.

4. Smoller JW, Finn CT. Family, twin, and adoption studies of bipolar disorder Am J Med Genet C Semin Med Genet. 2003;123C(1):48-58.

5. Buraei Z, Yang J. Structure and function of the beta subunit of voltagegated ca(2)(+) channels. Biochim Biophys Acta. 2013;1828(7):1530-40.

6. Lee MT, Chen CH, Lee CS, Chen CC, Chong MY, Ouyang WC, Chiu NY, Chuo $\sqcup$, Chen CY, Tan HK, et al. Genome-wide association study of bipolar I disorder in the Han Chinese population. Mol Psychiatry. 2011;16(5):548-56.

7. Jan WC, Yang SY, Chuang LC, Lu RB, Lu MK, Sun HS, Kuo PH. Exploring the associations between genetic variants in genes encoding for subunits of calcium channel and subtypes of bipolar disorder. J Affect Disord. 2014:157:80-6.

8. Zhang D, Raichle ME. Disease and the brain's dark energy. Nat Rev Neurol. 2010;6(1):15-28.

9. De Marco M, Vallelunga A, Meneghello F, Varma S, Frangi AF, Venneri A. ApoE epsilon4 allele related alterations in hippocampal connectivity in early Alzheimer's disease support memory performance. Curr Alzheimer Res. 2017;14(7):766-77.

10. Hariri AR, Drabant EM, Weinberger DR. Imaging genetics: perspectives from studies of genetically driven variation in serotonin function and corticolimbic affective processing. Biol Psychiatry. 2006;59(10):888-97.

11. Bearden CE, Freimer NB. Endophenotypes for psychiatric disorders: ready for primetime? Trends Genet. 2006:22(6):306-13.

12. Meyer-Lindenberg A. From maps to mechanisms through neuroimaging of schizophrenia. Nature. 2010;468(7321):194-202

13. Yan CG, Cheung B, Kelly C, Colcombe S, Craddock RC, Di Martino A, Li Q, Zuo XN, Castellanos FX, Milham MP. A comprehensive assessment of regional variation in the impact of head micromovements on functional connectomics. Neuroimage. 2013;76:183-201.

14. Tzourio-Mazoyer N, Landeau B, Papathanassiou D, Crivello F, Etard O, Delcroix N, Mazoyer B, Joliot M. Automated anatomical labeling of activations in SPM using a macroscopic anatomical parcellation of the MNI MRI single-subject brain. Neuroimage. 2002;15(1):273-89.

15. Liu H, Tang $Y$, Womer F, Fan G, Lu T, Driesen N, Ren L, Wang $Y$, He $Y$, Blumberg HP, et al. Differentiating patterns of amygdala-frontal functional connectivity in schizophrenia and bipolar disorder. Schizophr Bull. 2014; 40(2):469-77.

16. Casamassima F, Hay AC, Benedetti A, Lattanzi L, Cassano GB, Perlis RH. Ltype calcium channels and psychiatric disorders: a brief review. Am J Med Genet B Neuropsychiatr Genet. 2010;153B(8):1373-90.

17. Kato T. Molecular neurobiology of bipolar disorder: a disease of 'moodstabilizing neurons'? Trends Neurosci. 2008;31(10):495-503.

18. Bell DC, Butcher AJ, Berrow NS, Page KM, Brust PF, Nesterova A, Stauderman KA, Seabrook GR, Nurnberg B, Dolphin AC. Biophysical properties, pharmacology, and modulation of human, neuronal L-type (alpha(1D),
ca(V)1.3) voltage-dependent calcium currents. J Neurophysiol. 2001;85(2): 816-27.

19. Walker RM, Christoforou AN, McCartney DL, Morris SW, Kennedy NA, Morten $P$, Anderson SM, Torrance HS, Macdonald A, Sussmann JE, et al. DNA methylation in a Scottish family multiply affected by bipolar disorder and major depressive disorder. Clin Epigenetics. 2016;8:5.

20. Pereira LP, Kohler CA, de Sousa RT, Solmi M, de Freitas BP, Fornaro M, Machado-Vieira R, Miskowiak KW, Vieta E, Veronese N, et al. The relationship between genetic risk variants with brain structure and function in bipolar disorder: a systematic review of genetic-neuroimaging studies. Neurosci Biobehav Rev. 2017:79:87-109.

21. Soldatov NM. CACNB2: an emerging pharmacological target for hypertension, heart failure, arrhythmia and mental disorders. Curr Mol Pharmacol. 2015;8(1):32-42.

22. Rocher C, Spedding M, Munoz C, Jay TM. Acute stress-induced changes in hippocampal/prefrontal circuits in rats: effects of antidepressants. Cereb Cortex. 2004;14(2):224-9.

23. Karim HT, Wang M, Andreescu C, Tudorascu D, Butters MA, Karp JF, Reynolds CF 3rd, Aizenstein HJ. Acute trajectories of neural activation predict remission to pharmacotherapy in late-life depression. Neuroimage Clin. 2018;19:831-9.

24. Berridge MJ. Calcium signalling and psychiatric disease: bipolar disorder and schizophrenia. Cell Tissue Res. 2014;357(2):477-92.

25. Cipriani A, Saunders K, Attenburrow MJ, Stefaniak J, Panchal P, Stockton S, Lane TA, Tunbridge EM, Geddes JR, Harrison PJ. A systematic review of calcium channel antagonists in bipolar disorder and some considerations for their future development. Mol Psychiatry. 2016;21(10):1324-32.

26. Zhang XC, Woud ML, Becker ES, Margraf J. Do health-related factors predict major depression? A longitudinal epidemiologic study. Clin Psychol Psychother. 2018;25(3):378-87.

27. Marangoni C, Faedda GL, Baldessarini RJ. Clinical and environmental risk factors for bipolar disorder: review of prospective studies. Harv Rev Psychiatry. 2018;26(1):1-7.

28. Badre $D$, Wagner AD. Left ventrolateral prefrontal cortex and the cognitive control of memory. Neuropsychologia. 2007:45(13):2883-901.

29. Mechelli A, Crinion JT, Long S, Friston KJ, Lambon Ralph MA, Patterson K, McClelland $J \mathrm{~L}$, Price $C J$. Dissociating reading processes on the basis of neuronal interactions. J Cogn Neurosci. 2005;17(11):1753-65.

30. Maess B, Herrmann CS, Hahne A, Nakamura A, Friederici AD. Localizing the distributed language network responsible for the N400 measured by MEG during auditory sentence processing. Brain Res. 2006;1096(1):163-72.

31. Laroche S, Davis S, Jay TM. Plasticity at hippocampal to prefrontal cortex synapses: dual roles in working memory and consolidation. Hippocampus. 2000;10(4):438-46.

32. Thierry AM, Gioanni Y, Degenetais E, Glowinski J. Hippocampo-prefrontal cortex pathway: anatomical and electrophysiological characteristics. Hippocampus. 2000;10(4):411-9.

33. Jay TM, Rocher C, Hotte M, Naudon L, Gurden H, Spedding M. Plasticity at hippocampal to prefrontal cortex synapses is impaired by loss of dopamine and stress: importance for psychiatric diseases. Neurotox Res. 2004:6(3):233-44.

Ready to submit your research? Choose BMC and benefit from:

- fast, convenient online submission

- thorough peer review by experienced researchers in your field

- rapid publication on acceptance

- support for research data, including large and complex data types

- gold Open Access which fosters wider collaboration and increased citations

- maximum visibility for your research: over $100 \mathrm{M}$ website views per year

At $\mathrm{BMC}$, research is always in progress.

Learn more biomedcentral.com/submissions 